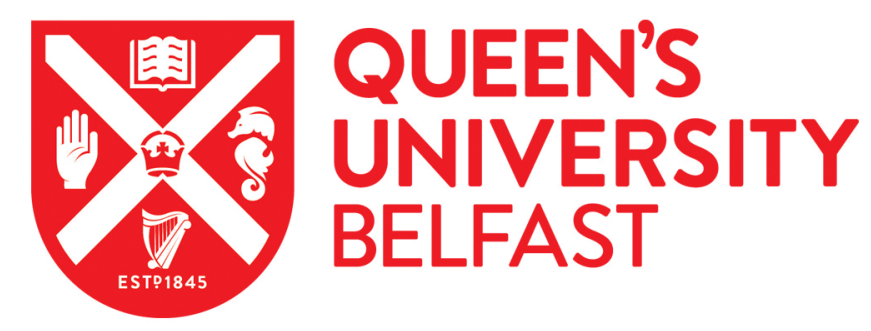

\title{
A durability performance-index for concrete: developments in a novel test method
}

McCarter, W. J., Chrisp, T. M., Starrs, G., Muhammed Basheer, P. A., Nanukuttan, S., Srinivasan, S., \& Magee, B. J. (2015). A durability performance-index for concrete: developments in a novel test method. International Journal of Structural Engineering, 6(1), 2-22. https://doi.org/10.1504/IJSTRUCTE.2015.067966

\section{Published in:}

International Journal of Structural Engineering

\section{Document Version:}

Early version, also known as pre-print

\section{Queen's University Belfast - Research Portal:}

Link to publication record in Queen's University Belfast Research Portal

\section{Publisher rights}

Copyright 2016 The Author

This is an open access article published under a Creative Commons Attribution-NonCommercial-NoDerivs License

(https://creativecommons.org/licenses/by-nc-nd/4.0/), which permits distribution and reproduction for non-commercial purposes, provided the author and source are cited.

\section{General rights}

Copyright for the publications made accessible via the Queen's University Belfast Research Portal is retained by the author(s) and / or other copyright owners and it is a condition of accessing these publications that users recognise and abide by the legal requirements associated with these rights.

Take down policy

The Research Portal is Queen's institutional repository that provides access to Queen's research output. Every effort has been made to ensure that content in the Research Portal does not infringe any person's rights, or applicable UK laws. If you discover content in the Research Portal that you believe breaches copyright or violates any law, please contact openaccess@qub.ac.uk. 
Reference to this paper should be made as follows: McCarter, W.J., Chrisp, T.M., Starrs, G., Basheer, P.A.M., Nanukuttan, S., Srinivasan, S. and Magee, B.J. (2015) 'A durability performance-index for concrete: developments in a novel test method', Int. J. Structural Engineering, Vol. 6, No. 1, pp.2-22. 


\title{
A DURABILITY PERFORMANCE-INDEX FOR CONCRETE: DEVELOPMENTS IN A NOVEL TEST METHOD
}

\begin{abstract}
Implementation of both design for durability and performance-based standards and specifications are limited by the lack of rapid, simple, science-based test methods for characterizing the transport properties and deterioration resistance of concrete. This paper presents developments in the application of electrical property measurements as a testing methodology to evaluate the relative performance of a range of concrete mixes. The technique lends itself to in-situ monitoring thereby allowing measurements to be obtained on the asplaced concrete. Conductivity measurements are presented for concretes with and without supplementary cementitious materials (SCM's) from demoulding up to 350-days. It is shown that electrical conductivity measurements display a continual decrease over the entire test period and attributed to pore structure refinement due to hydration and pozzolanic reaction. The term Formation Factor is introduced to rank concrete performance in terms of is resistance to chloride penetration.
\end{abstract}

Keywords: concrete, cover-zone, durability, performance testing, monitoring, electrical conductivity, Formation Factor. 


\subsection{INTRODUCTION}

European Standard EN206-1 (British Standards Institution, 2000a) deals with durability of concrete entirely on the basis of prescriptive specification of minimum grade, minimum binder content and maximum water-binder ratio for a series of well-defined environmental classes. Annex J within this code does give brief details of the approach and principles for performance-related design methods with respect to durability. Although numerous attempts have been made to introduce performance-based specifications, this has been hampered by the lack of reliable, consistent and standardised test procedures and protocols for evaluating concrete performance (Bentur and Mitchell, 2008). The Committee responsible for developing EN-206 recognised that an appropriate testing technology has not been sufficiently developed to satisfy performance-based philosophy (Hobbs, 1998). In this respect, there is widespread recognition that central to the concept of performance-based specifications is the requirement for reliable and repeatable test methods which can evaluate the required performance characteristic(s) along with performance compliance limits, which should take into account the inherent variability of the test method. It is evident that test procedures are required such that those properties of concrete which ensure long-term durability can be determined very early on in the life of a structure and that it will meet specified requirements (DuraCrete, 1999). The lack of adequate performance-related test methods is one of the main factors inhibiting the move from the prescriptive, deem-to-satisfy, approach to performance-based specifications.

Further to the above, there is also an intense need to evaluate the concrete earlier to obtain an early indication of potential concerns or, conversely, to gain early confidence that all is well. The sooner information is obtained about the early-age properties of any given batch of concrete, the sooner adjustments can be made to the materials, proportions or processes for subsequent concrete placement and the sooner remedial measures can be initiated on the concrete already installed or construction practices altered (e.g. extended curing). Early-age testing is useful in this regard and, indeed, absolutely essential as the consequences of unsatisfactory concrete discovered at a later stage becomes expensive. The term identity testing is used in BS 8500-1 (British Standards Institution, 2006a) to describe testing to validate the identity of the mix. Identity testing attempts to verify some key characteristic of the concrete that relates to the desired performance and could take the form of a slump, flow, density, strength, water-content or some non-destructive or in-place method. For example, consider a performance requirement for a concrete mix with an in-place chloride-ion 
diffusivity of, say, $3 \times 10^{-12} \mathrm{~m}^{2} / \mathrm{s}$, assuming that the mix had been pre-qualified based on preconstruction testing. During actual construction the challenge is to perform a test - or suite of tests - on concrete sampled at the time of placement which can then be used to verify that the concrete, as delivered, is substantially the same as the concrete that had previously been shown to meet the $3 \times 10^{-12} \mathrm{~m}^{2} / \mathrm{s}$ diffusivity requirement. There would, in addition, be a need to assess that the in-place concrete has a diffusivity of $3 \times 10^{-12} \mathrm{~m}^{2} / \mathrm{s}$ using appropriate testing techniques.

Sustainable concrete construction requires performance-based knowledge of expected durability and service-life; as a result, the quantification of concrete performance by means a single, easily measurable parameter is a subject of increasing interest. Moreover, since it is the cover-zone concrete which protects the steel from the external environment, the protective properties of this zone is crucial in attempting to make predictions as to the performance of the structure with regard to likely deterioration rates for a particular exposure condition and compliance with specified service-life. Regarding cover-zone properties, it is the permeation properties which are important and terms such as diffusivity, permeability and sorptivity are used in this respect. There clearly exists a need to study and determine quantitatively those near-surface characteristics of concrete which promote the ingress of gases or liquids containing dissolved contaminants and defining concrete performance in terms of a durability parameter which gives an assessment of these properties. Furthermore, evaluation of the long-term performance of the concrete without information on the in-situ properties of the prepared/placed concrete could result in an erroneous response.

To this end, developments in the use of electrical property measurements are presented as offering a potential performance-based testing technique and methodology for indexing the protective qualities of cover-zone concrete.

\subsection{BACKGROUND AND RATIONALE}

\subsection{Electrical properties of porous materials}

Conductivity is a fundamental property of a material and is related to the resistance, in ohms, between opposite faces of a unit cube of that material. If $\mathrm{R}$ is the bulk resistance of a prismatic sample of concrete contained between a pair of electrodes of area $\mathrm{A}\left(\mathrm{cm}^{2}\right)$, separated by a distance $L(\mathrm{~cm})$, then its bulk conductivity, $\sigma$, is given by,

$$
\sigma=\left(\frac{\mathrm{L}}{\mathrm{RA}}\right) \text { Siemens/cm }(\mathrm{S} / \mathrm{cm})
$$


Since the flow of water under a pressure differential (hence permeability) or the movement of ions under a concentration gradient (hence diffusion) is analogous to the flow of current under a potential difference (hence electrical resistance), it is understandable that the electrical properties of concrete could serve as a simple, yet effective, testing technique for assessing transport processes, hence performance and durability. Drawing an analogy between hardened concrete and rock (as both could be regarded as porous solids), conventional treatment of rock conductivity data has been to use the term formation factor (F) which is defined as the ratio of the conductivity of the saturating liquid $\left(\sigma_{\mathrm{p}}\right)$ to the bulk conductivity of the saturated rock $(\sigma)$ and linked to porosity, $\varphi$, through the empirical relationship (Archie, 1942),

$$
\mathrm{F}=\frac{\sigma_{\mathrm{p}}}{\sigma}=\varphi^{-\mathrm{m}}
$$

In this relationship, the exponent $m$ is related to the tortuosity and connectivity of the pore network within the rock with $m$ values lying, typically, in the range 1.5-2.5. Millington and Quirk (Millington and Quirk, 1962) have presented a relationship relating rock permeability, $\mathrm{k}\left(\mathrm{m}^{2}\right)$, to $\mathrm{F}$ and the average pore radius, $\mathrm{r}$, within the rock determined by mercury intrusion porosimetry as:

$$
\mathrm{F}=\frac{\mathrm{r}^{2}}{8 \mathrm{k}}
$$

The Katz-Thomson model (Katz and Thomson, 1986) for saturated porous systems introduces the term critical pore diameter and establishes a relationship between the permeability, $k(\mathrm{~m} / \mathrm{s})$, formation factor, $F$, and the critical pore diameter, $d_{c}$, within the system as,

$$
\mathrm{F}=\frac{1}{226 \mathrm{k}} \mathrm{d}_{\mathrm{c}}^{2}\left(\frac{\rho \mathrm{g}}{\eta}\right)
$$

where $\rho$ is the density of water; $g$ is the gravitational acceleration and $\eta$ the viscosity of the permeating fluid.

If the solid phase can be regarded as non-conductive in comparison to that of the interstitial pore-fluid, diffusivity and ionic conductivity of a saturated porous system are connected through the Nernst-Einstein relationship (see, for example, Atkinson and Nickerson, 1984; Christensen et al, 1994; Kyi and Batchelor 1994; Tumidajski and Schumacher 1996; Lu, 1997), 


$$
\frac{\sigma}{\sigma_{p}}=\frac{D}{D_{o}}=\tau
$$

where D is the diffusion coefficient of the porous system; $D_{0}$ the diffusion coefficient of the ion (e.g. $\mathrm{Cl}^{-}$) in the free electrolyte, and $\tau$ is termed the tortuosity; the ratio $\sigma / \sigma_{\mathrm{p}}$ thus represents the reciprocal of the formation factor.

\subsection{Further Considerations}

From an electrical point of view, concrete can be regarded as a composite comprising nonconductive aggregate particles embedded in an ionically conducting cementitious matrix. As a consequence, the hydration process will result in time-variant microstructural changes which will decrease capillary pore diameter, decrease in pore connectivity and increase pore tortuosity. Long-term pore structure refinement, beyond the post-curing period, will thus influence permeation properties and must be evaluated. This is particularly important for concretes containing supplementary cementitious materials (SCM) such as fly-ash or ground granulated blast-furnace slag.

In order to fully exploit electrical property measurements in assessing the relative performance of different concrete mixtures, the conductivity of the pore-fluid, $\sigma_{p}$, is required. For example, two concretes, with exactly the same underlying microstructure, could display different bulk conductivities due to differing pore-fluid chemistry which could, for example, result from differing ionic concentrations within the saturating pore fluid. This is particularly relevant when SCM's are used as these materials alter the concentrations of $\mathrm{Na}^{+}, \mathrm{K}^{+}$and $\mathrm{OH}^{-}$ within the interstitial aqueous phase in comparison to a plain Portland cement concrete.

In order to estimate the conductivity of the pore-fluid, pore expression techniques can be used (Barneybeck and Diamond, 1982). This is impractical for a variety of reasons, not least because it complicates the testing procedure. Furthermore, pore expression techniques are more applicable to cement-paste samples (not concretes) with relatively high water/binder ratios at the early stages of hydration. Under such circumstances, the pore-fluid conductivity could be estimated from the ionic concentration predicted from a model. For example, the model of Taylor (Taylor, 1987) predicts the concentration of various ionic species in the pore solution based on the cement composition and degree of hydration, and has been shown to be reasonably accurate (Reardon, 1992). From the estimated concentrations it is then possible to evaluate the conductivity of the pore-fluid. In this paper the model developed by Snyder 
(Snyder et al, 2003) and Bentz (Bentz, 2007) is used to estimate the conductivity of the pore fluid and discussed below.

\subsection{EXPERIMENTAL}

\subsection{Embedded Electrode Array}

To facilitate electrical measurements within the cover-zone, the Authors have modified a multi-electrode array (McCarter et al, 1995; Chrisp et al, 2002) which is embedded within concrete specimens at the time of casting. The array allows monitoring of the spatial distribution of both electrical resistance and temperature within the cover region. In summary, the array comprises six electrode-pairs mounted on a 'T-shaped' PVC former, with the former being secured on two steel bars $(1.5 \mathrm{~cm}$ diameter) as shown in Figure 1 ; the coverto-steel is $5.0 \mathrm{~cm}$. Four thermistors were also mounted on the array for temperature measurement.

The pairs of electrodes were positioned at discrete distances from the base of the former and were located at 1.0, 2.0, 3.0, 4.0, 5.0 and $7.5 \mathrm{~cm}$ from the concrete surface. A further two electrodes were positioned at a depth of $7.5 \mathrm{~cm}$ which, together with the electrode-pair positioned at $7.5 \mathrm{~cm}$, formed a set of four co-linear electrodes with a $1.0 \mathrm{~cm}$ spacing (see Figure 1. This configuration allowed 4-point electrical measurements at this depth and the conductivity of the concrete, $\sigma(\mathrm{S} / \mathrm{cm})$ could then be evaluated from the relationship (McCarter et al, 2009),

$$
\sigma=\frac{1}{4 \pi s R_{4 p t}} \mathrm{~S} / \mathrm{cm}
$$

where $s$ is the spacing between the electrodes $(=1 \mathrm{~cm})$ and $R_{4 p t}$ is the measured 4-point resistance, in ohms $(\Omega)$. Electrical measurements obtained at $7.5 \mathrm{~cm}$ are sufficiently remote from any effects at the concrete surface (e.g. drying, wetting) and will reflect cement hydration, pozzolanic reaction and microstructural development. This is discussed below.

The conductivity of the concrete at each electrode-pair can be evaluated by multiplying the measured resistance by a calibration factor (denoted $k_{\mathrm{f}}$ ). This was obtained by calibrating with the measured conductivity of $10 \mathrm{~cm}$ cubes cast from the same batch as the slabs used in the experimental programme (three cubes per mix). These cubes had four, embedded stainless steel pins to the same specification as those on the arrays. The pins were positioned centrally within the cube in a co-linear fashion and a centre-to-centre spacing of $1.0 \mathrm{~cm}$ (i.e. the same as the embedded array at $7.5 \mathrm{~cm}$ ) thereby allowing three resistance measurements to be 
obtained per cube. A 4-point technique using external stainless steel plates and the internal electrodes was used for evaluation of the concrete conductivity (McCarter et al, 2009) and subsequent evaluation of the electrode-pair calibration factor. Hence the measured resistance, $\mathrm{R}$ (ohms), across the electrode-pairs on the array could be converted to conductivity, $\sigma$ (in $\mathrm{S} / \mathrm{cm})$, through the relationship,

$$
\sigma=\frac{k_{f}}{R} \mathrm{~S} / \mathrm{cm}
$$

Figure 2 presents the calibration curve for the electrode-pair geometry used within the experimental programme with $x$ and $y$ error-bars representing one standard deviation; in those cases where the error bar appears to be missing, the data markers are larger than the error bar. In this Figure, the conductance $\left(=1 / R_{\text {conc }}\right.$, in Siemens) measured across the electrode-pairs within the concrete cubes is plotted against the conductivity of the concrete, $\sigma_{\text {conc, }}$ with the slope of the straight line being the calibration factor and is equivalent to the ratio L/A in equation (1) above. $k_{\mathrm{f}}$ was evaluated as $0.412 \mathrm{~cm}^{-1}$. The conductivity value was further crosschecked with 4-point measurements obtained from electrodes positioned at $7.5 \mathrm{~cm}$ on the array.

\subsection{Materials and Sample Preparation}

The concrete mixes used within the experimental programme are presented in Table 1 . The binders comprised Portland cement (PC) clinker, CEM I to EN197-1:2000 (British Standards Institution, 2000); CEM I cement blended with ground granulated blast-furnace slag (GGBS) to EN15167-1 (British Standards Institution, 2006); and CEM I cement blended with lowlime fly-ash (FA) to EN450-1 (British Standards Institution, 2005). Crushed granite aggregate was used throughout. A mid-range water reducer/plasticiser (SikaPlast 15RM) conforming to EN934-2 (British Standards Institution, 2009) was added by percentage mass of binder. The PC and SCM's were combined at the concrete mixer. The oxide analysis of the SCM's is presented in Table 2.

Specimens were cast as $25 \times 25 \times 15 \mathrm{~cm}$ (thick) slabs in steel formwork; the $25 \times 25 \mathrm{~cm}$ face cast against the formwork - which was to be used as the working face - had a small dyke cast around it to facilitate ponding. An electrode array was positioned at the plan centre of each slab with the steel reinforcing projecting out through the sides of the specimens; wiring from the embedded array was ducted out of the slab and terminated with a multipole D-connector. A total of 4 slab-specimens were cast for each mix on Table 1 together with nine, $10 \mathrm{~cm}$ cubes 
- six for compressive strength tests and three for calibration tests noted above. The 28-day and 180-days compressive strength is presented in Table 1 ( $f_{28}$ and $f_{180}$, respectively, in MPa).

\subsection{Testing Regime and Monitoring}

On demoulding at approximately 24-hours, each slab specimen was wrapped in damp hessian and placed in a heavy-duty polythene bag which was then sealed. The specimens were left in a laboratory at constant temperature $\left(20 \pm 1^{\circ} \mathrm{C}\right)$ for a period of 27 -days. At this time, the four vertical faces $(25 \times 15 \mathrm{~cm})$ of the specimens were painted with two coats of a proprietary sealant and exposed to a laboratory environment $20 \pm 1^{\circ} \mathrm{C}, 55 \% \pm 5 \% \mathrm{RH}$. After approximately 7-days, all samples were ponded with water for a period of 24-hours. This ensured the surface region of all specimens was in a similar saturated state. Samples were then allowed to dry for a further 7-days before being subjected to a cyclic ponding regime with salt solution to simulate natural environmental action. This regime was, generally, 1-day ponding followed by 6-days drying in the laboratory environment. A 0.55 Molar salt solution was used throughout (32g of sodium chloride per litre of distilled water).

Electrical resistance measurements were obtained by connecting the samples to a multiplexing system and an auto-ranging data logger. The resistance of the concrete between each electrode-pair was obtained a fixed frequency of $1 \mathrm{kHz}$; the signal amplitude was $350 \mathrm{mV}$ with a measurement integration time of 1.0 second. Thermistor measurements were also acquired using the same system which were subsequently converted to temperature in degrees Celsius. On demoulding at 24-hours, measurements were taken continuously on a 12-hour cycle for the duration of the test period. Periodically, 4-point measurements at $7.5 \mathrm{~cm}$ were obtained manually using an Agilent 4263B LCR meter.

\subsection{RESULTS AND DISCUSSION}

\subsection{Preliminaries}

This paper focusses on the response from the electrode-pairs positioned at $7.5 \mathrm{~cm}$ from the exposed surface of the specimens as, at this depth, they are sufficiently distant from the surface to be unaffected by the wetting/drying action at the surface. To highlight this point, Figure 3 presents the conductivity, $\sigma_{t}$, versus time response for the electrodes positioned at 1.0, 2.0 and $7.5 \mathrm{~cm}$ from the surface for the PC concrete $\operatorname{mix}(\mathrm{w} / \mathrm{b}=0.65)$. For illustrative purposes, data are presented between 100 and 300 days after casting. For reasons of clarity, the measurement points at $1.0 \mathrm{~cm}$ and $2.0 \mathrm{~cm}$ have been removed and only every $10^{\text {th }}$ measurement point is highlighted on the response at $7.5 \mathrm{~cm}$. The influence of the cyclic 
wetting/drying regime on the conductivity of the concrete is clearly evident for the electrodes positioned $1.0 \mathrm{~cm}$ and $2.0 \mathrm{~cm}$ from the surface, with periods of wetting resulting in an increase in conductivity and drying accompanied by a decrease in conductivity. The electrodes positioned at $7.5 \mathrm{~cm}$, however, display a continual decrease with time and remain unaffected by wetting/drying at the concrete surface. Similar responses were obtained for the other concrete mixes and it is for this reason that measurements from the electrode-pair positioned at $7.5 \mathrm{~cm}$ from the exposed surface, and still within the near-surface region, are presented within this paper.

Based on the resistance values obtained at each electrode-pair positioned within the surface $7.5 \mathrm{~cm}$, and using equation (7) above, the average 28-day conductivity for the concrete within the surface $7.5 \mathrm{~cm}$ is presented Table 3 . Also presented in Table 3 are the conductivity values evaluated at $7.5 \mathrm{~cm}$ using 4-point resistance measurements and equation (6) above. Both methods show good agreement in estimating the concrete conductivity at this position within the cover-zone.

\subsection{Temporal change in conductivity}

Electrical conduction through concrete will be primarily via the connected capillary porosity within the binder which, itself, will be influenced by hydration and pozzolanic reaction. This will result in time-variant microstructural changes to the pore network and will be reflected in a temporal decrease in the measured conductivity. The conductivity $\left(\sigma_{t}\right)$ of the concrete mixes in Table 1 is presented in Figures 4 and 5 and, as noted above, based on the values obtained from the electrode-pair positioned at $7.5 \mathrm{~cm}$.

Figure 4(a) displays the variation in conductivity for concrete mixes with $w / b=0.35$ over the initial 27-days after demoulding. In general terms, the conductivity of all mixes display a continual decrease although the influence of binder composition on conductivity is also clearly evident during the initial curing period. For periods $<3$ days, the PC concrete displays a lower conductivity than the FA/35 and GGBS/65 concrete mixes and reflects the initial slower reaction of these blended systems. However, for periods $>3$-days, the conductivity of the GGBS/65 concrete achieves lower values than the PC concrete whereas for the FA/35 concrete, this effect does not occur until approximately 15 days. Similar trends are observed in Figure 4(b) for concrete mixes with w/b=0.65 although the conductivity of the FA/35 mix only achieves lower values than the PC mix at periods in excess of 28-days. It is also 
observed that an increase in the w/b ratio results in an increase in the conductivity of the concrete.

Figures 5(a) and (b) display the conductivity (at 7.5cm from the surface) from 10-days up to approximately 350 days for, respectively, 0.35 and $0.65 \mathrm{w} / \mathrm{b}$ ratio. It is during this period that curing measures were removed (at 28-days) from the specimens and the surface subjected to a cyclic wetting and drying regime. It is apparent that this has not had any effect on the conductivity of the concrete at this depth as there are no 'abrupt' changes in the conductivity at 28-days and the ensuing period; this further corroborates the discussion of Figure 3 above. Both Figure 5(a) and (b) display a continual decrease in conductivity over the entire period indicating on-going hydration and pozzolanic reaction.

The influence of SCM's on the conductivity is clearly displayed in these Figures; at the end of the test period, the conductivity of the FA/35 and GGBS/65 concrete mixes are almost an order of magnitude less than the PC concrete mix, at both w/b ratios. The decrease in conductivity for both the slag and fly-ash concretes reflects the on-going pore structure refinement during the post-curing period. Although such concretes may not necessarily be of lower total porosity than the PC concretes, it is of a much more discontinuous and tortuous nature, due to the ongoing reactions within the existing pore structure ( $\mathrm{Li}$ and Roy, 1986).

The decrease in conductivity for the concretes presented in Figure 5 can be represented by the equation:

$$
\sigma_{t}=\sigma_{r e f}\left(\frac{t_{r e f}}{t}\right)^{n}
$$

where, $\sigma_{\mathrm{t}}$ is the conductivity at time, $\mathrm{t}$ (in days); $\sigma_{\text {ref }}$ is the conductivity at a reference time,

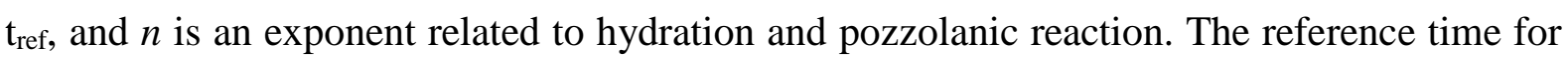
the current work is taken as 28-days, hence $t_{\text {ref }}=28$ days and $\sigma_{\text {ref }}$ values are presented in Table 3 (2-point). Best-fit curves to the data are plotted on Figure 5(a) and (b) as dashed lines through the measurement points and the fitting equations are presented on these Figures. It is interesting to observe that for a particular cementitious binder, the exponent, $n$, for both w/b ratios are similar i.e. $n$ is independent of $\mathrm{w} / \mathrm{b}$ ratio.

Although the equations on these Figures were developed on the best-fit line to all the data points for a particular w/b ratio (i.e. over 700 measurement points), a curve can be evaluated from fewer measurements, which has obvious practical implications. For example, Figures 6(a) and (b) present the best-fit curves (solid lines) based on conductivity measurements at 
10, 20 and 28 days (3 measurement points) using the same reference time of 28-days. For comparative purposes, the best-fit curves based on all the measurement points on Figure 5 are also presented on Figure 6 (dashed lines).

\subsection{Conductivity and Diffusion}

Equation (5) above highlights the interrelationship between conductivity and diffusion coefficient of a saturated porous material. A conductivity measurement must thus give an indirect assessment of the instantaneous diffusion coefficient of the concrete. However, to fully implement equation (5) the conductivity of the pore-water, $\sigma_{\mathrm{p}}$, must be known or, at least, assessed.

Due to both the practicality and considerable difficulty in expressing pore solution from concrete, the conductivity of the pore water can be estimated from the contributions to conductivity of the major ions in the pore water, namely, sodium $\left(\mathrm{Na}^{+}\right)$, potassium $\left(\mathrm{K}^{+}\right)$and hydroxyl $\left(\mathrm{OH}^{-}\right)$. A straightforward procedure for estimating pore solution conductivity from the concentrations of these ions in the pore-water has been developed by Snyder (Snyder et al, 2003) and Bentz (Bentz, 2007). In summary, for a particular degree of hydration, the concentrations of $\mathrm{Na}^{+}$and $\mathrm{K}^{+}$in the pore-water are computed from the binder composition and assuming that $75 \%$ of the sodium and potassium initially present as oxides in the cementbased materials will be released into the pore-water. The concentration of $\mathrm{OH}^{-}$is deduced from the electroneutrality condition. These data are then used to compute the pore solution electrical conductivity, viz,

$$
\sigma_{p}=\sum_{i} z_{i} c_{i} \lambda_{i}
$$

where $\mathrm{z}_{\mathrm{i}}, \mathrm{C}_{\mathrm{i}}$, and $\lambda_{\mathrm{i}}$ are, respectively, the ionic species valence, molar concentration and equivalent conductivity associated with each ion, $i$. The equivalent conductivity is then computed from,

$$
\lambda_{i}=\frac{\lambda_{i}^{0}}{1+G_{i} \sqrt{I_{M}}}
$$

The values of $\lambda_{i}^{0}$ - the equivalent conductivity of an ionic species at infinite dilution - and the conductivity coefficient, $\mathrm{G}_{\mathrm{i}}$ for $\mathrm{Na}^{+}, \mathrm{K}^{+}$, and $\mathrm{OH}^{-}$ions are presented in Table 4 (Snyder et al, 2003). The quantity $I_{M}$ is the ionic strength (molar basis) and has the following definition,

$$
I_{M}=\frac{1}{2} \sum_{i} z_{i}^{2} c_{i}
$$


Based on this model, and the oxide analysis of the cementitious materials used in the experimental programme (Table 2), the estimated conductivity values of the pore-water at selected degrees of hydration are presented in Figures 7(a)-(c) for PC, FA/35 and GGBS/65 binders. Values are plotted over the range 50\%-95\% hydration which represents, approximately, the degree of hydration over the time-scale 7-days to 180-days (Hewlett, 1998; Lin and Meyer, 2009). It is evident from Figure 7 that hydration has little effect on the pore-water conductivity, particularly at the higher w/b ratio where the conductivity remains virtually constant. At $\mathrm{w} / \mathrm{b}=0.35$, the conductivity of the pore-water increases by approximately $30 \%$ as the degree of hydration increases from $50 \%$ to $95 \%$.

From equations (5) and (8), it is now possible to obtain an approximation for the instantaneous diffusion coefficient at time, $t$, denoted $\mathrm{D}_{\mathrm{i}}(\mathrm{t})$, as,

$$
D_{i}(t)=D_{o} \frac{\sigma_{r e f}}{\sigma_{p}}\left(\frac{t_{r e f}}{t}\right)^{n}
$$

Consider the PC concrete with $\mathrm{w} / \mathrm{b}=0.35$. If, over the test period, an average degree of hydration of $75 \%$ is assumed then, following the work of Snyder (Snyder et al, 2003), the conductivity of the pore-water, $\sigma_{\mathrm{p}}$, is evaluated as $0.091 \mathrm{~S} / \mathrm{cm}$. If the self-diffusion of the chloride ion $\left(\mathrm{Cl}^{-}\right)$in pure water, $\mathrm{D}_{0}$, is assumed to be $1.84 \times 10^{-9} \mathrm{~m}^{2} / \mathrm{s}$ ( $\mathrm{Li}$ and Gregory, 1974; Shackleford and Daniel, 1991), then, from Figure 5(a) and equation (12),

$$
D_{i}(t)=\frac{\left(1.84 \times 10^{-9}\right) \times\left(1.38 \times 10^{-4}\right)}{0.091}\left(\frac{28}{t}\right)^{0.26} \mathrm{~m}^{2} / \mathrm{s}
$$

Hence,

$$
D_{i}(t)=2.80 \times 10^{-12}\left(\frac{28}{t}\right)^{0.26} \mathrm{~m}^{2} / \mathrm{s}
$$

Repeating the same process for the remaining mixes obtains the curves presented in Figures 8(a) and (b) and plotted on a log-log scale.

The diffusion coefficient obtained above would represent the instantaneous diffusion coefficient and should not be confused with the effective diffusion coefficient, $\mathrm{D}_{\text {eff, }}$ which is generally referred to in the literature. $D_{\text {eff }}$ is normally obtained from the error function solution to the chloride profile obtained from dust drillings taken through the cover-zone. With reference to Figure 9, $\mathrm{D}_{\text {eff }}$ represents the integrated, or time-averaged, diffusion coefficient and would be related to the instantaneous diffusion coefficient, $\mathrm{D}_{\mathrm{i}}(\mathrm{t})$, by,

$$
D_{e f f}=\frac{1}{\left(t-t_{e x}\right)} \int_{t_{e x}}^{t} D_{i}(t) d t
$$


where $t_{\mathrm{ex}}$ is the concrete age at first exposure to chlorides. At short exposure times, $\mathrm{D}_{\mathrm{eff}} \approx \mathrm{D}_{\mathrm{i}}$; however, it is evident from Figure 9 that as the exposure time increases i.e. $\left(t-t_{e x}\right)$ increases, then $\mathrm{D}_{\text {eff }}$ will tend to underestimate the diffusion coefficient at the time of measurement. If $D_{\text {eff }}$ values are used to make predictions as to future chloride ingress they will tend to be conservative estimates, i.e. they will underestimate the time to activation of corrosion.

It is accepted that the evaluation of the conductivity of the pore-water is, at best, approximate, however, considering the extremely wide variation in published values for diffusion coefficients for concretes with and without SCM's (Bamforth et al, 1997), evaluation of the diffusion coefficient using this methodology could represent a good estimate.

\subsection{Towards a Performance-Based Index}

From the definition of formation factor (F) in equation (2) above, and the relationship of this parameter with tortuosity and diffusivity through equation (5), it should be possible to rank concrete in terms of its resistance to chloride penetration; in other words, the greater the $\mathrm{F}$ value, the better the performance of the concrete in terms of chloride resistance. Table 5 presents the computed $F$ values for each concrete mix in Table 1 at both 28-days $\left(F_{28}\right)$ and 180-days $\left(\mathrm{F}_{180}\right)$; as before, an average degree of hydration of $75 \%$ for each binder type has been assumed throughout in calculating $\sigma_{\mathrm{p}}$.

With reference to Table 5, decreasing the w/b ratio from 0.65 to 0.35 results in, approximately, a fivefold increase in F for each mix. Moreover, the beneficial effect of the fly-ash and slag is clearly evident, particularly at longer time-scales. It is interesting to note that whilst the GGBS/65 concrete displays the lowest bulk conductivity value, when the conductivity of the pore-water is considered, it is out-ranked by the FA/35 concrete in the longer-term.

\section{CONCLUDING COMMENTS}

The work detailed above has presented developments in the application of electrical property measurements as a potential test method to rank the relative performance of a range of concrete mixes. This was undertaken through a combination of bulk conductivity measurements together with an estimated value for the pore-fluid conductivity; these values were then used to assess concrete performance in terms of diffusivity and Formation Factor (F). In general terms, the lower the $\mathrm{F}$ value for the concrete, the poorer its performance rating; however, work is still required to obtain values or range of values for $\mathrm{F}$ for concrete classification purposes. 
The following general conclusions can be drawn:

(1) A 4-point and a 2-point technique were used to obtain the in-situ conductivity of the concrete, with both methods giving similar values. Unlike the 4-point method, however, the 2-point method required prior calibration.

(2) A general equation has been presented to model the temporal decrease in conductivity. An ageing factor was introduced to account for conductivity versus time response.

(3) The decrease in electrical conductivity reflected on-going hydration and pore structure refinement within the binder and extended over the duration of the test programme (which was approximately 350-days).

(4) Those concretes containing SCM's displayed a more marked decrease in conductivity than the plain PC mix and was attributed to the pozzolanic reaction and resulting influence on the pore network in terms of decreasing connectivity and increasing tortuosity and constriction. 


\section{REFERENCES}

Archie G. E. (1942). 'The electrical resistivity log as an aid in determining some reservoir characteristics', Trans. of the Amer. Inst. of Mining and Metallurgical Engrs., 146, 54-62.

Atkinson, A. and Nickerson, A. K. (1984). 'The diffusion of ions through water-saturated cement', J. of Matls. Sci., 19(9), 3068-3078.

Bamforth, P. B., Price W. F. and Emerson, M. (1997). 'An international review of chloride ingress into structural concrete', Transport Research Laboratory, Contractor Report 359, 162pp, (ISSN 0266-7045).

Barneyback, R.S. and Diamond, S. (1981). 'Expression and analysis of pore fluid from hardened cement pastes and mortars', Cem. Concr. Res., 11(2), 279-285.

Bentur, A. and Mitchell D. (2008). 'Materials performance lessons', Cem. Concr. Res., 38(2), 259-272, (2008).

Bentz, D. (2007). 'A virtual rapid chloride permeability test', Cem. Concr. Comp., 29(10), 723-731.

British Cement Association, (1998). 'Minimum requirements for durable concrete', Ed. By D. W. Hobbs, British Cement Association, 172pp.

British Standards Institution, EN206-1: (2000a). 'Concrete: Specification, performance, production and conformity', BSI, London.

British Standards Institution, EN197-1. (2000b). 'Cement-Part 1: Composition, specifications and conformity criteria for common cements', BSI, London.

British Standards Institution, EN450-1. (2005). 'Fly ash for concrete-Part 1: Definition, specifications and conformity criteria’, BSI, London.

British Standards Institution, BS8500-1. (2006a). 'Concrete-Complementary British Standard to EN 206-1 - Part 1: Method of specifying and guidance for the specifer', BSI, London.

British Standards Institution, EN15167-1. (2006b). 'Ground granulated blast furnace slag for use in concrete, mortar and grout - Part 1: Definitions, specifications and conformity criteria', BSI, London.

British Standards Institution, EN934-2. (2009). 'Admixtures for concrete, mortar and grout. Part 2: Concrete admixtures', BSI, London. 
Chrisp T. M., McCarter W. J., Starrs G., Basheer, P. A. M. and Blewett J. (2002). 'Depth related variation in conductivity to study wetting and drying of cover-zone concrete', Cem. Concr. Comp., 24(5), 415-427.

Christensen, B. J., Coverdale, R. T., Olsen, R. A., Ford, S. J., Garboczi, E. J., Jennings, H. M., Mason, T. O. (1994). 'Impedance spectroscopy of hydrating cement-based materials: measurement, interpretation, and applications', J. Amer. Ceramic Soc., 77(11), 2789-2804.

DuraCrete (1999). 'Compliance testing for probabilistic Design purposes' EU Brite-EuRam III, Project Report BE95-1347/R8, 105pp (ISBN 903760420X).

Hewlett, P. C. (Editor) (1998). Chapter 4 in 'Lea's Chemistry of Cement', ButterworthHeinemann, Oxford, UK, $4^{\text {th }}$ Edition (ISBN 0750662565).

Hobbs, D. W. (Editor) (1998). 'Minimum requirements for durable concrete: Minimum requirements for durable concrete carbonation- and chloride-induced corrosion, freeze-thaw attack and chemical attack, British Cement Association, 172pp (ISBN 0721015247, 9780721015248).

Katz, A. J. and Thompson, A. H. (1986). 'Quantitative prediction of permeability in porous rock', Phys. Rev. B: Condensed Matter, 34(11), 8179-8181.

Kyi, A. A., Batchelor, B. (1994). 'An electrical conductivity method for measuring the effects of additives on effective diffusivities in Portland cement pastes', Cem. Concr. Res., 24(4), 752-764.

Li, S. and Roy, D. M. (1986). 'Investigation of relations between porosity, pore structure, and $\mathrm{Cl}$ - diffusion of fly ash and blended cement pastes', Cem. Concr. Res., 16(5), 749-759.

Li, Y-H. and Gregory, S. (1974). 'Diffusion of ions in sea water and deep-sea sediments', Geochimica et Cosmochemica Acta, 38, 703-714.

Lin, F. and Meyer,C. (2009). 'Hydration kinetics modeling of Portland cement considering the effects of curing temperature and applied pressure', Cem. Concr. Res., 39(4), 255-265.

Lu, X. (1997). 'Application of the Nernst-Einstein equation to concrete', Cem. Concr. Res., 27(2), 293-302.

McCarter, W. J., Emerson, M. and Ezirim, H. (1995), 'Properties of concrete in the cover zone: developments in monitoring techniques', Mag. Concr. Res., 47(172), 243-251. 
McCarter, W.J., Starrs, G., Kandasami, S., Jones, M. R. and Chrisp, M. (2009). 'Electrode configurations for resistivity measurements on concrete', ACI Matls. J., 106(3), 258-264.

Millington R. J. and Quirk J. P. (1964). 'Formation factors and permeability equations', Nature, 202, 4928, 11 April, 143-145.

Reardon, E. J. (1992). 'Problems and approaches to the prediction of the chemical composition in cement/water systems', Waste Management, 12, 221-239.

Shackelford, C. D. and Daniel, D. E., (1991). 'Diffusion in saturated soil I: Background'. ASCE J. of Geotechnical Engng., 117(3), 467-484.

Snyder, K.A., Feng, X., Keen, B.D. and Mason, T.O. (2003). 'Estimating the electrical conductivity of cement paste pore solutions from $\mathrm{OH}^{-}, \mathrm{K}^{+}$and $\mathrm{Na}^{+}$concentrations', Cem. Concr. Res., 33(6), 793-798.

Taylor, H.F.W. (1987). 'A method for predicting alkali ion concentrations in cement pore solutions', Adv. Cem. Res., 1(1), 5-16.

Tumidajski, P. J., Schumacher, A. S. (1996). 'On the relationship between the formation factor and propan-2-ol diffusivity in mortars', Cem. Concr. Res., 26(9), 1301-1306. 
Table 1. Summary of concrete mixes. Materials are presented in $\mathrm{kg} / \mathrm{m}^{3} ; \mathrm{pl}=$ plasticiser and $\mathrm{w} / \mathrm{b}=$ water-binder ratio.

\begin{tabular}{l|c|c|c|c|c|c}
\hline Mix Ref: & \multicolumn{2}{|c|}{ PC } & \multicolumn{2}{c|}{ FA/35 } & \multicolumn{2}{c}{ GGBS/65 } \\
\hline w/b & 0.35 & 0.65 & 0.35 & 0.65 & 0.35 & 0.65 \\
\hline PC & 378 & 263 & 242 & 169 & 132 & 92 \\
\hline FA & - & - & 130 & 91 & - & - \\
\hline GGBS & - & - & - & - & 224 & 170 \\
\hline pl (\%) & 1.43 & - & 1.43 & - & 1.43 & - \\
\hline Fine (<4mm) & 787 & 790 & 773 & 780 & 782 & 786 \\
\hline $10 \mathrm{~mm}$ & 393 & 395 & 386 & 390 & 391 & 393 \\
\hline $20 \mathrm{~mm}$ & 787 & 790 & 773 & 780 & 782 & 786 \\
\hline$f_{28}$ & 79 & 39 & 81 & 35 & 65 & 31 \\
\hline$f_{180}$ & 88 & 46 & 89 & 45 & 76 & 40 \\
\hline
\end{tabular}

Table 2. Oxide analysis of materials used in experimental programme ( $+=$ not determined)

\begin{tabular}{c|c|c|c}
\hline \% by weight & PC & FA & GGBS \\
\hline $\mathrm{SiO}_{2}$ & 20.68 & 51.0 & 34.33 \\
\hline $\mathrm{Al}_{2} \mathrm{O}_{3}$ & 4.83 & 27.4 & 12.60 \\
\hline $\mathrm{Fe}_{2} \mathrm{O}_{3}$ & 3.17 & 4.6 & 0.60 \\
\hline $\mathrm{CaO}$ & 63.95 & 3.4 & 41.64 \\
\hline $\mathrm{MgO}$ & 2.53 & 1.4 & 8.31 \\
\hline $\mathrm{TiO}_{2}$ & + & 1.6 & + \\
\hline $\mathrm{P}_{2} \mathrm{O}_{5}$ & + & 0.3 & + \\
\hline $\mathrm{SO}_{3}$ & 2.80 & 0.7 & + \\
\hline $\mathrm{K}_{2} \mathrm{O}$ & 0.54 & 1.0 & 0.47 \\
\hline $\mathrm{Na}_{2} \mathrm{O}$ & 0.08 & 0.2 & 0.25 \\
\hline
\end{tabular}


Table 3. Averaged concrete conductivity at 28-days $\left(\sigma_{28}\right)$ after casting based on electrodepair measurements within the surface $7.5 \mathrm{~cm}$ (2-point) and 4-point measurements at $7.5 \mathrm{~cm}$. (The number in brackets is the standard deviation for results).

\begin{tabular}{c|c|c|c}
\hline \multirow{2}{*}{ Mix } & w/b ratio & $\begin{array}{c}\frac{\text { 2-point }}{\sigma_{28}} \\
\left(\times 10^{-4} \mathrm{~S} / \mathrm{cm}\right)\end{array}$ & $\begin{array}{c}\frac{\text { 4-point }}{\sigma_{28}} \\
\left(\times 10^{-4} \mathrm{~S} / \mathrm{cm}\right)\end{array}$ \\
\hline \multirow{2}{*}{$\mathrm{PC}$} & 0.35 & $1.38(0.14)$ & $1.40(0.11)$ \\
\cline { 2 - 4 } & 0.65 & $2.72(0.23)$ & $3.09(0.21)$ \\
\hline \multirow{2}{*}{ FA/35 } & 0.35 & $1.05(0.05)$ & $1.12(0.09)$ \\
\cline { 2 - 4 } & 0.65 & $2.54(0.20)$ & $2.66(0.15)$ \\
\hline \multirow{2}{*}{ GGBS/65 } & 0.35 & $0.31(0.20)$ & $0.32(0.02)$ \\
\cline { 2 - 4 } & 0.65 & $0.59(0.04)$ & $0.69(0.04)$ \\
\hline
\end{tabular}

Table 4. Equivalent conductivity at infinite dilution and conductivity coefficients for $\mathrm{Na}^{+}$, $\mathrm{K}^{+}$and $\mathrm{OH}^{-}$ions at $25^{\circ} \mathrm{C}$.

\begin{tabular}{c|c|c}
\hline Species & $\lambda^{\mathrm{o}}\left(\mathrm{cm}^{2} \mathrm{~S} / \mathrm{mol}\right)$ & $\mathrm{G}(\mathrm{mol} / \mathrm{L})^{-1 / 2}$ \\
\hline $\mathrm{Na}^{+}$ & 50.1 & 0.733 \\
\hline $\mathrm{K}^{+}$ & 73.5 & 0.548 \\
\hline $\mathrm{OH}^{-}$ & 198 & 0.353 \\
\hline
\end{tabular}


Table 5. Computed formation factors $(F)$ for the concrete mixes in Table 1 at 28-days $\left(F_{28}\right)$ and 180-days $\left(\mathrm{F}_{180}\right)$ after casting (75\% degree of hydration assumed throughout).

\begin{tabular}{c|c|c|c|c|c|c}
\hline Mix Ref: & \multicolumn{2}{|c|}{ PC } & \multicolumn{2}{c|}{ FA/35 } & \multicolumn{2}{c}{ GGBS/65 } \\
\hline $\mathrm{w} / \mathrm{b}$ & 0.35 & 0.65 & 0.35 & 0.65 & 0.35 & 0.65 \\
\hline $\begin{array}{c}\sigma_{\mathrm{p}} \\
(\mathrm{S} / \mathrm{cm})\end{array}$ & 0.091 & 0.041 & 0.120 & 0.054 & 0.035 & 0.016 \\
\hline $\begin{array}{c}\sigma_{28} \\
\left(\times 10^{-4} \mathrm{~S} / \mathrm{cm}\right)\end{array}$ & 1.38 & 2.72 & 1.05 & 2.54 & 0.31 & 0.59 \\
\hline $\begin{array}{c}\sigma_{180} \\
\left(\times 10^{-4} \mathrm{~S} / \mathrm{cm}\right)\end{array}$ & 0.86 & 1.75 & 0.15 & 0.34 & 0.14 & 0.25 \\
\hline $\mathrm{F}_{28}$ & 659 & 151 & 1143 & 213 & 1129 & 271 \\
\hline $\mathrm{F}_{180}$ & 1058 & 234 & 8000 & 1588 & 2500 & 640 \\
\hline
\end{tabular}




\section{FIGURE CAPTIONS}

Figure 1. Embedded electrode array

Figure 2. Calibration curve for electrode array used in experimental programme (error bars represent one standard deviation).

gure 3. Conductivity versus time response for electrodes positioned at $1.0,2.0$ and $7.5 \mathrm{~cm}$ from surface for PC concrete specimens $(\mathrm{w} / \mathrm{b}=0.65)$ undergoing cyclic ponding.

Figure 4. Decrease in conductivity during initial 28-days after casting for (a) w/b=0.35 and (b) $\mathrm{w} / \mathrm{b}=0.65$.

Figure 5. Decrease in conductivity during 10-400 days after casting for (a) w/b $=0.35$ and (b) w/b $=0.65$.

Figure 6. Curve-fits to conductivity versus time response based on 3 (three) measurement points at 10, 20 and 28-days for (a) w/b $=0.35$ and (b) w/b $=0.65$.

Figure 7. Calculated pore-water conductivity for the cementitious binders used within the experimental programme for (a) PC, (b) FA/35 and (c) GGBS/65.

Figure 8. Estimated diffusion coefficient based on conductivity measurements for concrete, (a) $\mathrm{w} / \mathrm{b}=0.35$ and $(\mathrm{b}) \mathrm{w} / \mathrm{b}=0.65$.

Figure 9. Schematic showing the relationship between $\mathrm{D}_{\text {eff }}$ and $\mathrm{D}_{\mathrm{i}}$. 
Electrodes positioned at $7.5 \mathrm{~cm}$ from

surface for 2-point and 4-point measurements

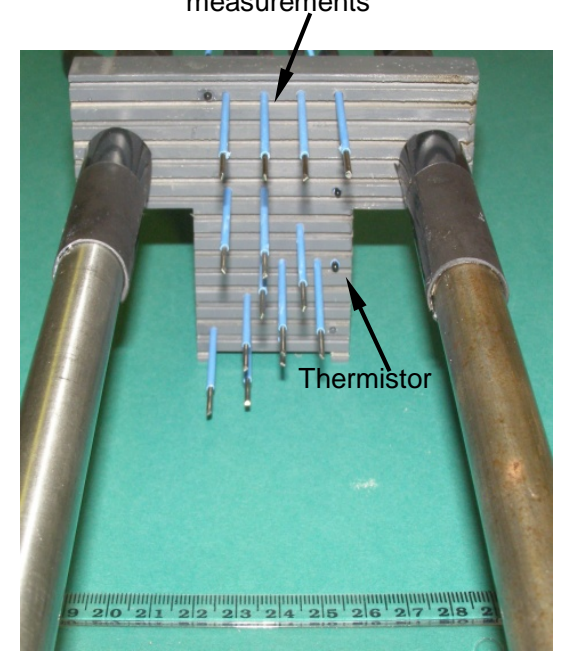

Figure 1 


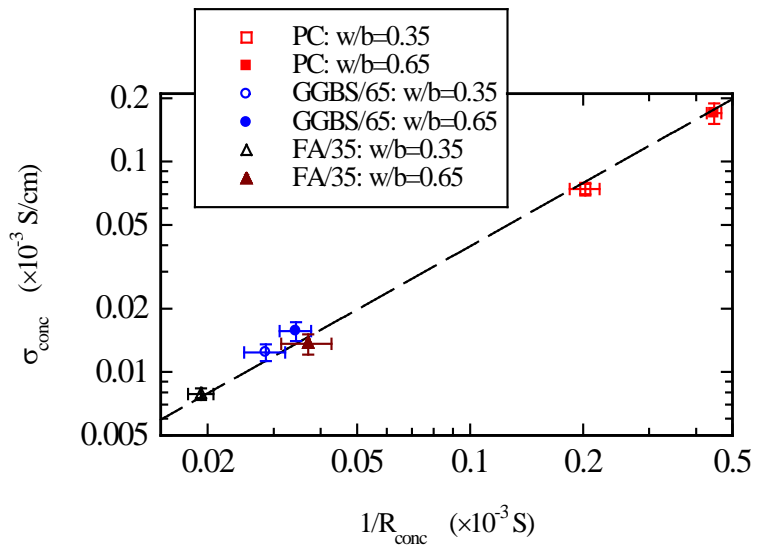

Figure 2 


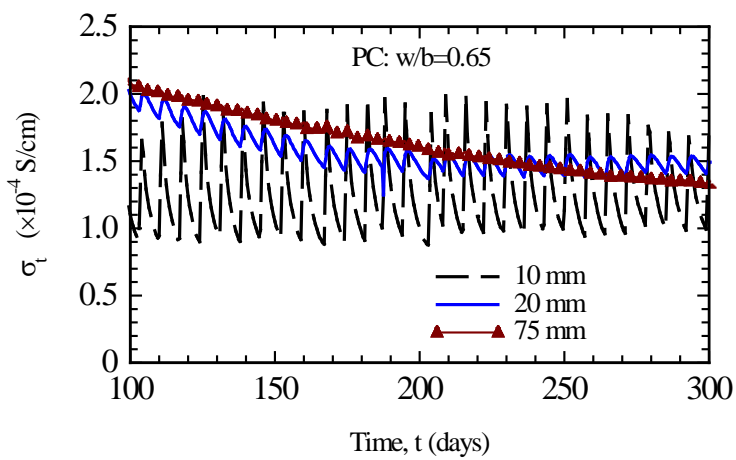

Figure 3 

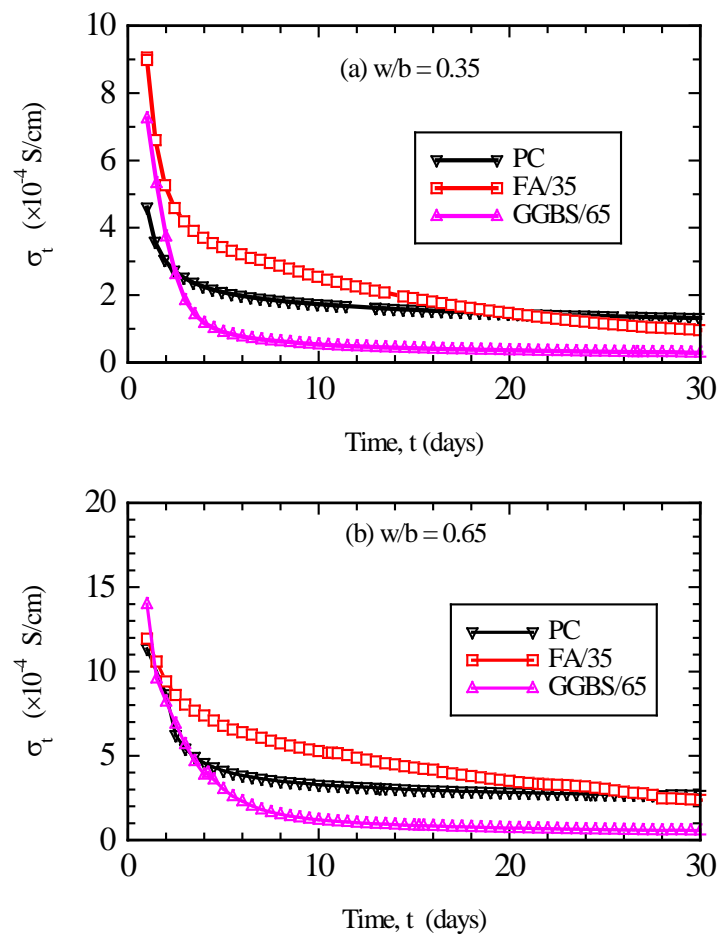

Figure 4 

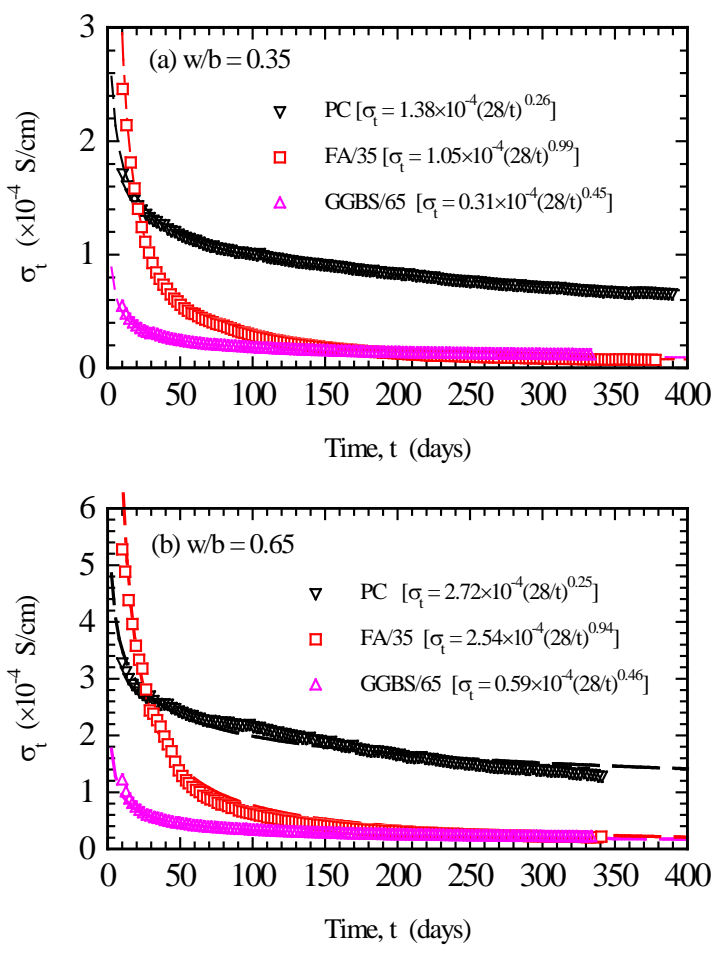

Figure 5 

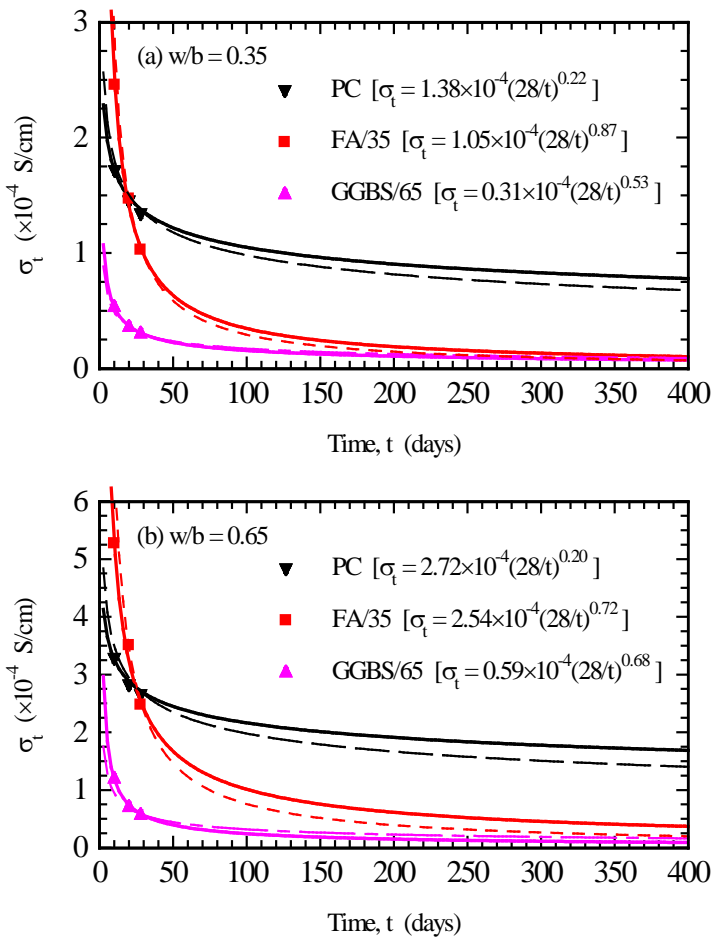

Figure 6 

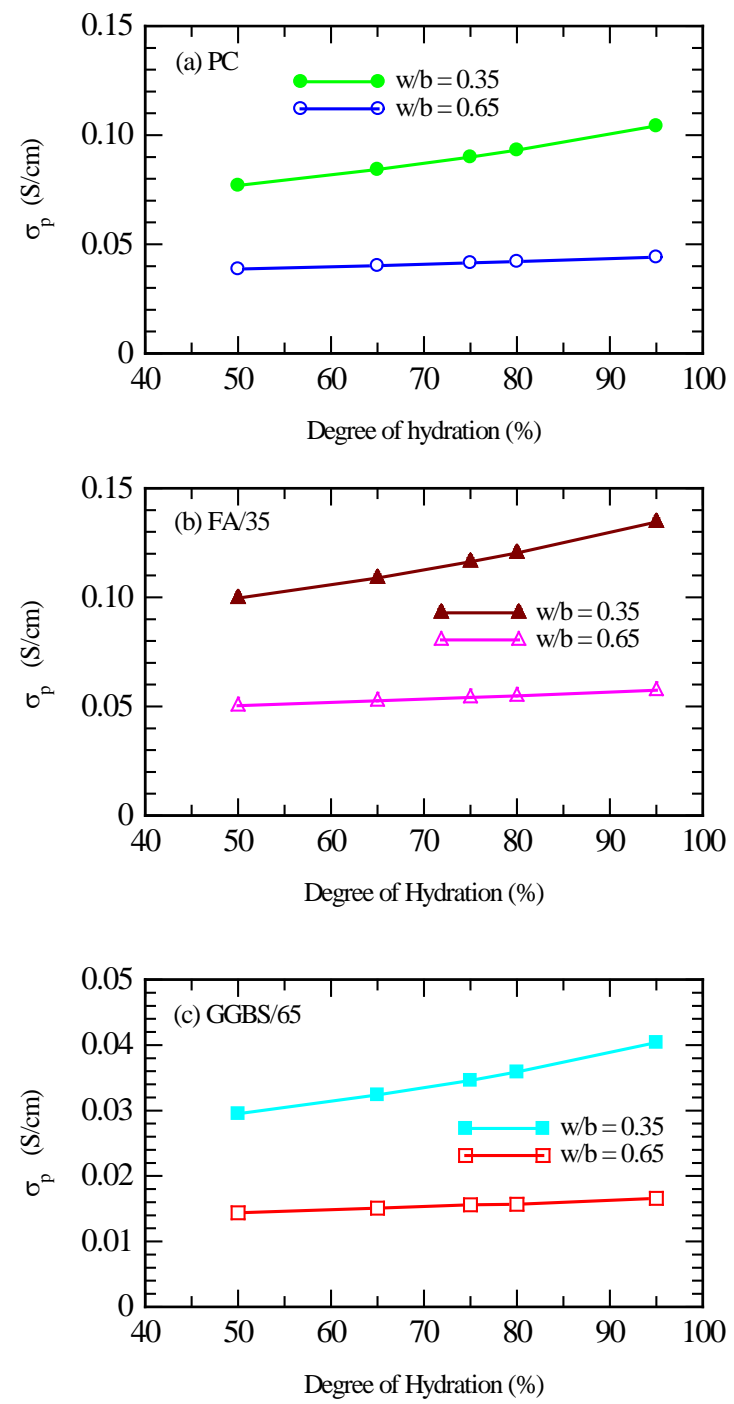

Figure 7 

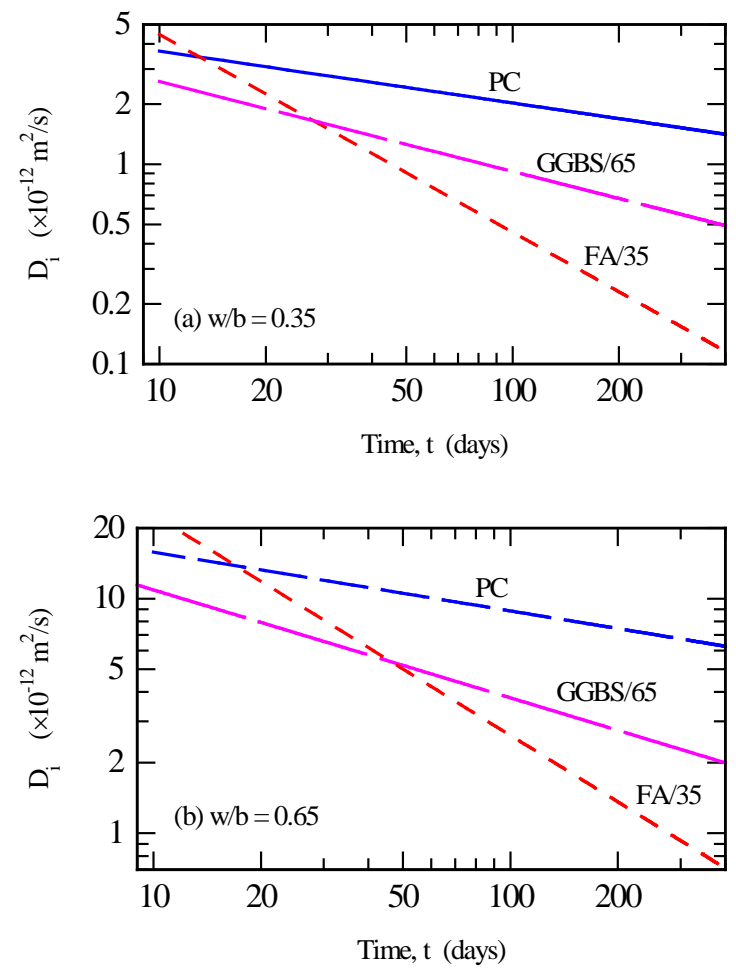

Figure 8 


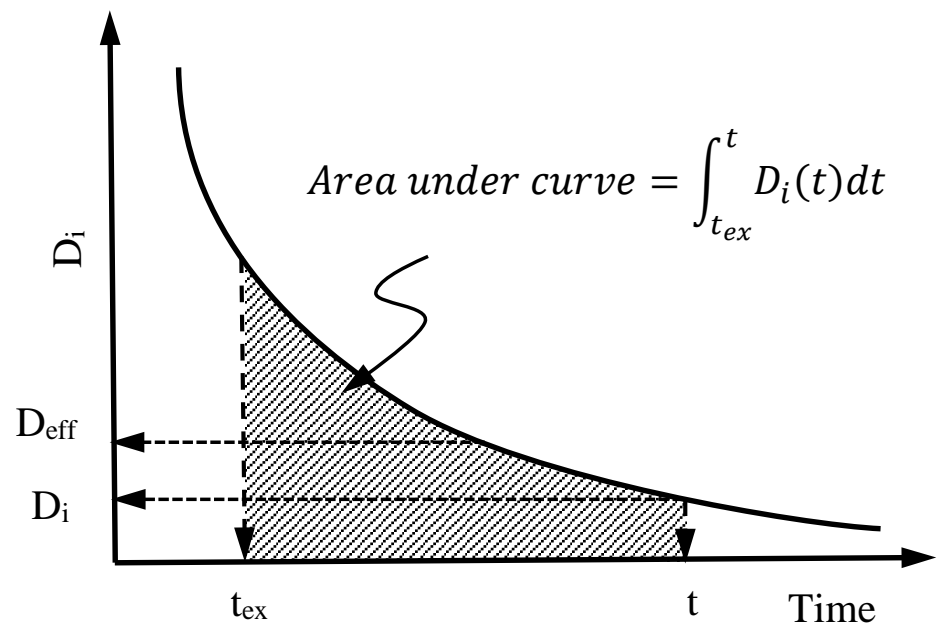

Figure 9 